\title{
Colorado Family Practice Graduates' Preparation for and Practice of Emergency Medicine
}

\author{
William L. Hall, MD, and David Nowels, $M D, M P H$
}

Background: Family physicians provide care in emergency departments, especially in rural areas; however, no published data describe how they perceive their preparation for emergency practice. We surveyed graduates of Colorado family practice residencies concerning their emergency medicine practice, their comfort working in emergency departments, and their perceived preparation for practicing emergency medicine.

Metbods: Seventy recent graduates of Colorado residencies were surveyed regarding their location, work in emergency departments, contact with emergency medical services (EMS) personnel, and perceptions about their emergency medical training.

Results: Forty-five percent of respondents practiced in rural settings, $33 \%$ worked in emergency departments (56\% rural, $14 \%$ urban), $60 \%$ reported contact with EMS personnel (91\% rural, 32\% urban), $54 \%$ believed their training adequately prepared them for working in emergency departments $(82 \%$ rural vs $32 \%$ urban), $63 \%$ of rural and $22 \%$ of urban respondents indicated they wanted more major trauma experience during training, $70 \%$ reported discomfort with managing trauma, and $44 \%$ were interested in a 6-month emergency medicine fellowship.

Conclusions: Most respondents believed their training in emergency medicine was adequate; however, most also reported discomfort with trauma management. Improved training for family physicians who provide emergency care could include expanded trauma care opportunities, increased work with EMS personnel, and postresidency training. (J Am Board Fam Pract 2000;13:246 -50.)

Family physicians have always provided emergency medical services to their patients and communities. With the expansion of emergency medicine as a specialty and accompanying changes in certification and credentialing of physicians working in emergency departments, fewer family physicians are staffing urban emergency departments. ${ }^{1}$ For rural emergency departments, however, it is difficult to recruit and compensate board-certified emergency physicians..$^{2-4}$ Recognizing this difficulty, the state trauma system guidelines for Colorado established an alternative, rural, level III trauma center credentialing pathway. The level III trauma designation allows some patients who would otherwise be transported to a higher level trauma center to be

Submitted, revised 8 March 2000.

From the Department of Emergency Medicine (WLH), University of Texas, Southwestern, Dallas, and the Department of Family Medicine (DN), University of Colorado Health Sciences Center, Denver. Address reprint requests to David Nowels, MD, MPH, Department of Family Medicine, Box B155, University of Colorado Health Sciences Center, 1180 Clermont, Denver, CO 80220.

Much of this work was accomplished while Dr. Hall was a Family Medicine Scholar, sponsored by the Department of Family Medicine at the University of Colorado Health Sciences Center. treated at their local hospital. ${ }^{5}$ Effective 1 July 1997, this pathway allows rural hospitals having appropriate surgical backup to staff their emergency departments with physicians board-certified in emergency medicine, surgery, internal medicine, or family medicine. Family physicians provide coverage in $30 \%$ to $80 \%$ of rural emergency departments ${ }^{2-4}$ and will continue to provide emergency medical care to the rural population for the foreseeable future both in Colorado and nationally.

Despite the ongoing presence of family physicians as providers of emergency care, very little has been published about their preparation for providing these services. Several studies have evaluated the care provided by rural physicians for trauma patients before their transfer to a trauma center. ${ }^{6-10}$ One survey addressed the overall training of rural family physicians, including their training for emergency medicine, ${ }^{11}$ and found that training to be nearly adequate. That study was limited by low response rates. We found no published reports addressing the specifics of family physicians' perceptions about their training for and practice of emergency medicine. Unpublished data we collected from graduating residents in family practice 
suggested that (1) they felt unsure their training was sufficiently adequate to allow them to function in emergency departments, (2) they were uncomfortable with managing major trauma, and (3) they had little contact with the emergency medical system (EMS) during their training.

The purpose of this study is to describe the experiences of new graduates from Colorado family practice residencies in providing emergency care and the graduates' perceptions of their preparedness for practicing emergency medicine. Comparisons are drawn from the experiences and perceptions of graduates practicing in rural and urban settings.

\section{Methods}

In May 1998 we mailed a 15 -item questionnaire to all 1997 graduates of Colorado family practice residencies. We chose a 1-year postresidency interval because we expected that respondents' recall of residency training would be high and the potential confounding of practice experience (as opposed to residency training) would be least. We surveyed the 1997 cohort for practical reasons and because the year coincided with enactment of the Colorado state trauma system guidelines. We obtained the names and addresses of each graduate $(n=76)$ from the Colorado Commission on Family Medicine. Most survey questions were forced choice and asked about the graduate's preparation for and practice of emergency medicine, but some survey items elicited written comments as well. We did not define any terms in the questionnaire (eg, rural, contact with EMS personnel, emergency department time). Instead, we allowed the respondents to interpret the questions from their own point of view, because we were attempting to learn their perspectives about their work. Eight weeks after the initial mailing, we sent a follow-up letter and questionnaire to nonresponders. We returned questionnaires with less than $75 \%$ of items answered to the responders and requested their completion. Each mailing included a stamped, selfaddressed return envelope.

We obtained additional data on residency training by reviewing brochures describing each residency program, contacting program directors and coordinators, and reviewing a pregraduation survey of the same cohort of 1997 graduates at the end of their third year of family practice residency (unpublished).
Table 1. Characteristics of Respondents $(n=70)$.

\begin{tabular}{lcc}
\hline Category & Number & Percent \\
\hline Respondents & 51 & 67 \\
Female respondents & 26 & 52 \\
Rural practice & 23 & 45 \\
Work in emergency department & 17 & 33 \\
Work in emergency department with & 8 & 45 \\
$\quad \geq 10,000$ patients per year & & \\
Practicing in Colorado & 34 & 68 \\
Community residency program & 38 & 71 \\
Residency program required trauma & 8 & 16 \\
$\quad$ rotation & & \\
Residency program required ATLS & 6 & 12 \\
$\quad$ certification & & \\
Average required weeks in emergency & 7 & \\
department during residency & & \\
\hline
\end{tabular}

ATLS = Advanced Trauma Life Support.

We entered data from the survey instruments into an electronic spreadsheet and then transported the data into SPSS for Windows for analysis. ${ }^{12}$ The analysis of responses was primarily descriptive. First, we examined the frequency of responses. We then compared the responses of the rural with those of the urban physicians using the $\chi^{2}$ test.

\section{Results}

Six physicians had incomplete addresses and were excluded from the survey. Fifty-one of the remaining 70 participants returned their questionnaires, a $67 \%$ response rate. Fifty-two percent of respondents were female and $48 \%$ were male; nonrespondents had a similar distribution. Sixty-eight percent of respondents practiced in Colorado. Two programs required a trauma rotation and another required Advanced Trauma Life Support (ATLS) training. A summary of respondents' characteristics is displayed in Table 1.

\section{Experience With Providing Emergency Medical Care}

Forty-five percent of respondents indicated that they practiced in a rural area. There was no significant difference between the proportion of women (42\%) and men $(50 \%)$ in rural practice. For respondents practicing in Colorado, $29 \%$ worked in rural areas. In contrast, $81 \%$ of those practicing outside Colorado worked in rural areas.

Although $57 \%$ reported they would take a job requiring them to work in an emergency department, only $33 \%$ actually provided care in that set- 
ting. The difference between the proportion of women $(27 \%)$ and men $(42 \%)$ providing care in an emergency department was not statistically significant. A significantly higher percentage of physicians working in rural practice also worked in an emergency department compared with urban physicians $(56 \%$ vs $14 \%, P=.002)$. For most respondents who worked in an emergency department, that work accounted for more than $10 \%$ of their total practice time.

Seventy percent of all respondents reported that of all aspects of providing emergency care, they were least comfortable managing trauma, with an equal percentage of rural and urban physicians reporting this discomfort. Other uncomfortable aspects of providing emergency care were reported less often: $18 \%$ reported discomfort with management of medical emergencies, $18 \%$ with the lack of continuity, and $10 \%$ with the time constraints of working in emergency departments.

\section{Contact With the Emergency Medical System}

Nearly one third of respondents indicated they would consider working as a physician advisor for an ambulance service, although only 1 had assumed that role. Overall, $60 \%$ of respondents reported contact with EMS personnel in their first year of practice. Significantly more rural physicians than urban physicians reported contact with EMS personnel $(91 \%$ vs $32 \%$ respectively, $P=.000$ ).

\section{Training}

Fifty-four percent of all respondents indicated that their training appropriately prepared them for working in emergency departments. Significantly more rural than urban physicians believed they were adequately prepared ( $82 \%$ vs $32 \%, P=.001$ respectively). Overall, $40 \%$ indicated that their training for emergency medicine was "just right." Another $40 \%$ reported that more experience with major trauma would have strengthened their training in emergency medicine, and again, we noted a difference between rural and urban physicians (63\% vs $22 \%, P=.009$ ). Eighteen percent reported that they would have liked to have spent more time in emergency departments during their training, with no difference between rural and urban physicians.

We asked respondents whether they would consider taking a 6- to 12-month emergency medical fellowship. Overall, $44 \%$ indicated that they would, with no significant difference between rural and urban physicians ( $56 \%$ vs $33 \%$, respectively). Thirty-six percent of those who said they would be interested in such a fellowship (16\% of all survey respondents) indicated they would be interested in additional training only if it led to board eligibility.

\section{Discussion}

Our study offers some insight into family physicians' practice of and preparation for delivery of emergency medical care shortly after their residency. The data we report can inform the educational and policy issues developing around the delivery of emergency care, especially the issues of who should deliver trauma care and in what settings. In brief, we found that (1) most respondents were comfortable providing emergency care, (2) most had contact with EMS personnel (3) most believed a focus on management of major trauma would have strengthened their residency training, and (4) physicians practicing in rural environments described important differences in the provision of emergency care compared with those practicing in urban environments.

Our study has several limitations. The most notable is the relatively small sample size. Our goal, however, was to learn about the experiences of family physicians trained in Colorado. The generalizability of these data is unclear because of the size and geographic limitations of the sample. Despite these limitations, the data describe recent family practice graduates' perceived competence, satisfaction with emergency care training, and identification of potential areas for enhanced training-the types of data for which surveys like ours are most appropriate.

These survey data generally support Colorado's current training of family practice residents in the area of emergency services. Training for trauma care, however, should be enhanced for those graduates who will provide emergency care, usually those in rural practice. This finding is consistent with those of previous studies in which rural family physicians described training for trauma care as an area for improvement. ${ }^{11}$ In rural areas trauma accounts for up to $17 \%$ of all visits to emergency departments, with major trauma accounting for up to $20 \%$ of injury visits to emergency departments. ${ }^{10}$ Further, a clear relation exists between degree of rurality and increased death rates from 
trauma. ${ }^{13}$ Our unpublished pregraduation survey data show that residents almost always know whether they will be providing emergency services after graduation. More training in trauma management would enhance both the confidence and competence of family physicians, who often provide emergency services in practice. ${ }^{14}$

Our survey results suggest several issues that should be addressed in expanding trauma education for those who will provide emergency care.

First, family practice residents should be given responsibility for the initial evaluation and stabilization of trauma patients. This responsibility should include performing diagnostic and therapeutic procedures. To facilitate acquisition of the knowledge and skills necessary for trauma care, family practice residents should participate in a trauma rotation during the latter part of their training, when they are among the more senior residents in the emergency department. The experience could be compulsory for rural-bound residents and optional for others.

Second, Advanced Trauma Life Support (ATLS) courses should be encouraged. These courses have been shown to increase participants' confidence and capability to deal with traumatic emergencies, and ATLS is believed to decrease mortality and improve pretransfer stabilization of trauma victims. ${ }^{6,7,13-15}$ Colorado trauma system guidelines for rural level III trauma centers require ATLS certification for physicians staffing those emergency departments. ${ }^{5}$ Courses leading to ATLS certification are readily accessible. The cost associated with requiring ATLS certification, however, has been raised as an issue by residency program directors and might explain why only one Colorado program required ATLS certification of their graduates.

Third, prehospital contact between residents and EMS personnel should be enhanced. Development of the knowledge base and management skills required for on-line medical control of EMS personnel during training is preferable to learning on the job without support or supervision. By graduation, only 1 resident reported riding in an ambulance, and $20 \%$ had contact with EMS personnel (unpublished data), yet $60 \%$ of our survey respondents reported contact with EMS personnel in practice.

The survey data also address some issues related to postgraduate education. More than $40 \%$ of the respondents were willing to complete additional extensive emergency medical training, especially if doing so led to board certification. Although American Board of Emergency Medicine certification is not currently possible without completing an emergency medicine residency, other forms of recognition for additional training, perhaps similar to a certificate of added qualification, should be considered.

\section{Conclusions}

Although most Colorado family practice residents are satisfied with the emergency medical training they received during residency, they report that trauma management is an area that needs improvement. Establishing a designated third-year trauma rotation, adding ATLS courses, and enhancing contact with EMS personnel would benefit residents who will be providing emergency medical services after leaving residency, especially those who will work in rural areas. Offering additional, postresidency training in emergency medicine, particularly training that leads to professional recognition, might prove to be a welcome addition for family physicians who provide emergency services.

\section{References}

1. Meislin HW, Munger BS. Emergency medicine 2000: residencies, resident graduates, and $\mathrm{ABEM}$ diplomates. Ann Emerg Med 1993;22:132-4.

2. Williamson HA, Rosenblatt RA, Hart LG. Physician staffing of small rural hospital emergency departments: rapid change and escalating costs. J Rural Health 1992;8:171-7.

3. Haskins RJ, Kallail KJ. Staffing in small rural hospital emergency rooms: dependence on community family physicians. Fam Pract Res J 1994;14:67-75.

4. McGirr J, Williams JM, Prescott JE. Physicians in rural West Virginia emergency departments: residency training and board certification status. Acad Emerg Med 1998;5:333-6.

5. Colorado Board of Health. Designation of trauma facilities. In: Rules and regulations pertaining to the statewide trauma system. Denver: State of Colorado, 1998:chap 3.

6. Martin GD, Cogbill TH, Landercasper J, Strutt PJ. Prospective analysis of rural interhospital transfer of injured patients to a referral trauma center.J Trauma 1990;30:1014-9.

7. Certo TF, Rogers FB, Pilcher DB. Review of care of fatally injured patients in a rural state: 5-year followup. J Trauma 1983;23:559-65.

8. Hicks TC, Danzl DF, Thomas DM, Flint LM. Re- 
suscitation and transfer of trauma patients: a prospective study. Ann Emerg Med 1982;11:296-9.

9. Larson DM, Mellstrom MS. Management of multiple trauma in a rural setting. Minn Med 1987;70: 43-5.

10. Perry BC, Chrisinger EW, Gordon MJ, Henze WA. A practice based study of trauma in a rural community. J Fam Pract 1980;10:1039-43.

11. Norris TE, Coombs JB, Carline J. An educational needs assessment of rural family physicians. J Am Board Fam Pract 1996;9:86-93.
12. SPSS for Windows, version 9. Chicago: SPSS, Inc, 1999.

13. Rutledge R, Fakhry SM, Baker CC, et al. A population-based study of the association of medical manpower with county trauma death rates in the United States. Ann Surg 1994;219:547-63.

14. Ali J, Howard M. The Advanced Trauma Life Support Program in Manitoba: a 5-year review. Can J Surg 1993;36:181-3.

15. Collicott PE, Hughes I. Training in advanced trauma life support. JAMA 1980;243:1156-9. 